\title{
Environmental odour monitoring by electronic nose
}

\author{
Zarra T. ${ }^{1}$, Cimatoribus C. ${ }^{2,}{ }^{*}$, Naddeo V. ${ }^{1}$, Reiser M. ${ }^{3}$, Belgiorno V. ${ }^{1}$ and Kranert M. ${ }^{3}$ \\ ${ }^{1}$ Sanitary Environmental Engineering Division (SEED), Department of Civil Engineering, Università degli Studi di Salerno, via Giovanni \\ Paolo II, 132-84084 Fisciano (SA), Italy \\ 2Building Services Energy Environment, University of Applied Sciences - Hochschule Esslingen, Kanalstraße, 33-73728 Esslingen, \\ Germany \\ 3ISWA Institut, Department of Civil Engineering, Stuttgart University, Bandtäle 1, 2, 70569 Stuttgart, Germany \\ Received: 14/06/2018, Accepted: 17/09/2018, Available online: 07/11/2018 \\ *to whom all correspondence should be addressed: e-mail: Carla.Cimatoribus@hs-esslingen.de \\ https://doi.org/10.30955/gnj.002794
}

\section{Abstract}

Odour emissions from industrial plants affect air quality and are consequently cause of a growing number of public complaints. The control of odour represents a key issue in plant management. The starting point for an effective odour control is their objective measurement. The electronic nose represents probably the odour monitoring technique with the greatest potential, but currently there is not a universally recognized procedure for their application in the continuous characterization of environmental odours.

The paper aims to present a novel procedure for training electronic noses in order to maximize their capability of operating a qualitative classification and estimating the odour concentration of ambient air. This novel approach reduces the uncertainty and increases the reliability of the continuous odour measures.

The Electronic Nose (E.Nose) seedOA realized by the Sanitary Environmental Engineering Division (SEED) of the University of Salerno was applied to a real case in a large wastewater treatment plant. The papers highlights the characterization of the odour concentrations from the different treatment units and the identification of the principal odour sources.

Keywords: Air quality, dynamic olfactometry, odour impact, sensor array, public complaints.

\section{Introduction}

Odour emissions from industrial plants are causes of conflict by the community living surrounding the plants and of complaints at the local authorities (Zarra et al., 2008; Belgiorno et al., 2012). The prolonged exposure to environmental odours causes a variety of undesirable reactions in people, including unease, headaches, respiratory problems, nausea or vomiting (Zarra et al., 2008). The particular and complex nature of the volatile substances, their variability on the time, the strong influence from atmospheric conditions and the subjectivity of smell perception all delayed their regulations (Zarra et al., 2008). Nowadays the available techniques for ambient odour measurements are classifiable in analytical, sensorial and sensor-instrumental (Belgiorno et al., 2012; Zarra et al., 2014). Analytical measurements allow the characterization of odours in terms of chemical composition (GC-MS, colorimetric methods). Sensory measurements, such as dynamic olfactometry standardized by EN13725:2003, provide for using human nose as sensor, defining and measuring the effects of the odours on a panel of qualified examiners. Sensorinstrumental techniques allows defining information about the chemical composition and the smell propriety of the investigated odour. The Electronic Nose (e.nose) appears as the sensor-instrumental technique with the most suitable potential. In fact, the use of the e.nose technology allows having a continuous and real time (or "near real time") monitoring of odours (Munoz et al., 2010; Romain et al., 2010).

According to Gardner and Bartlett (1994) an e.nose system consists of an array of non-specific gas sensors, a signal collecting unit and a pattern recognition software. The 'heart' of the E.Nose technologies is their measurement chamber with the inner sensor array, designed to detect and discriminate complex odour mixtures (Rock et al., 2008). Different numbers of sensors create the characteristic response called "fingerprint". Moreover, the different types of sensors commercially available use a range of materials, including metal oxides, conducting polymers, surface acoustic wave devices and catalytic metals (Rock et al., 2008; Munoz et al., 2010).

The principal steps in the application of e.nose technologies consist of an initial training phase and a subsequent on site measurement application. The training of the e.nose represents the most important phase of the whole process (Romain et al., 2010; Giuliani et al., 2012).

The goal of the training phase is to create the site-specific 'odour measurement model' (OMM) that are robust, repeatable and reliable. Different statistical techniques can be used to process the sampled data and define a qualitative and a quantitative OMM. The qualitative OMM has the objective to discriminate the different odour 
classes (e.g. odour sources) into a spatial domain, while the quantitative OMM aims at defining the correlation equation between the electrical signal data, acquired through the sensor array, and a measure of the 'odour characteristics'. In the current applications of the e.nose in the environmental fields, the e.nose data metrics are usually related to the Odour Concentration $\left(\mathrm{OU} / \mathrm{m}^{3}\right)$ measured with dynamic olfactometry, according to EN 13725:2003.

Nowadays there are no regulations or guidelines that standardise the odour measurement in ambient air with this type of instruments. In May 2015, a new CEN/TC264 'Air Quality' standardisation working group (WG41) started to define a new European standard for the use of instrumental odour monitoring in ambient air, indoor air and gas emissions, but they are still at work (Guillot, 2016). Likewise, there are currently no universally adopted and approved procedure that deals and regulates the training phase, the performance and the requirement of an e.nose. The definition of key points in order to guarantee an efficient and reliable measure with the e.nose is therefore a critical issue for the scientific community.

The present work illustrates a novel procedure to training electronic noses in order to maximize their capability of operating a qualitative classification and estimating the odour concentration of ambient air. The proposed procedure optimises the performance of the e.nose system studying their best sensor array selection. The aim of the research is to reduce the uncertainty and increase the reliability of the continuous odour measures.

\section{Materials and methods}

\subsection{Experimental setup and program}

Research activities were carried out at a real liquid waste treatment plant (LWTP), located in the municipality of Buccino, in the province of Salerno (Campania Region, IT). The LWTP has a design capacity of 60.000 p.e. (population equivalent) and an average daily flow rate of $6.600 \mathrm{~m}^{3} / \mathrm{d}$. The plant includes different treatment lines and an activated-sludge process.

To test the experimental hypothesis, six odour emission sources have been monitored in the LWTP, four of which related to the waste-wastewater treatment line (P1, waste influent; $P 2$, equalization basin; $P 3$, primary sedimentation; $\mathrm{P} 4$, aeration basin) and two to the sludge treatment line (P5, sludge thickening; P6, sludge dewatering by belt press) (Figure 1). In addition, in order to create the 'blank' point in the e.nose measurement model, non-odour samples in number of 5 for each campaign, were collected in one considered odourless place of the plant area (Romain et al., 2010; Giuliani et al., 2012). The plant was monitored through a weekly sampling campaign over a period of 2 months, in which nine samples were taken for each investigated odour sources. Air samples were collected according to EN 13725:2003, using the 'lung' technique, using Nalophan ${ }^{\circledR}$ sampling bags with 10 litres volume.
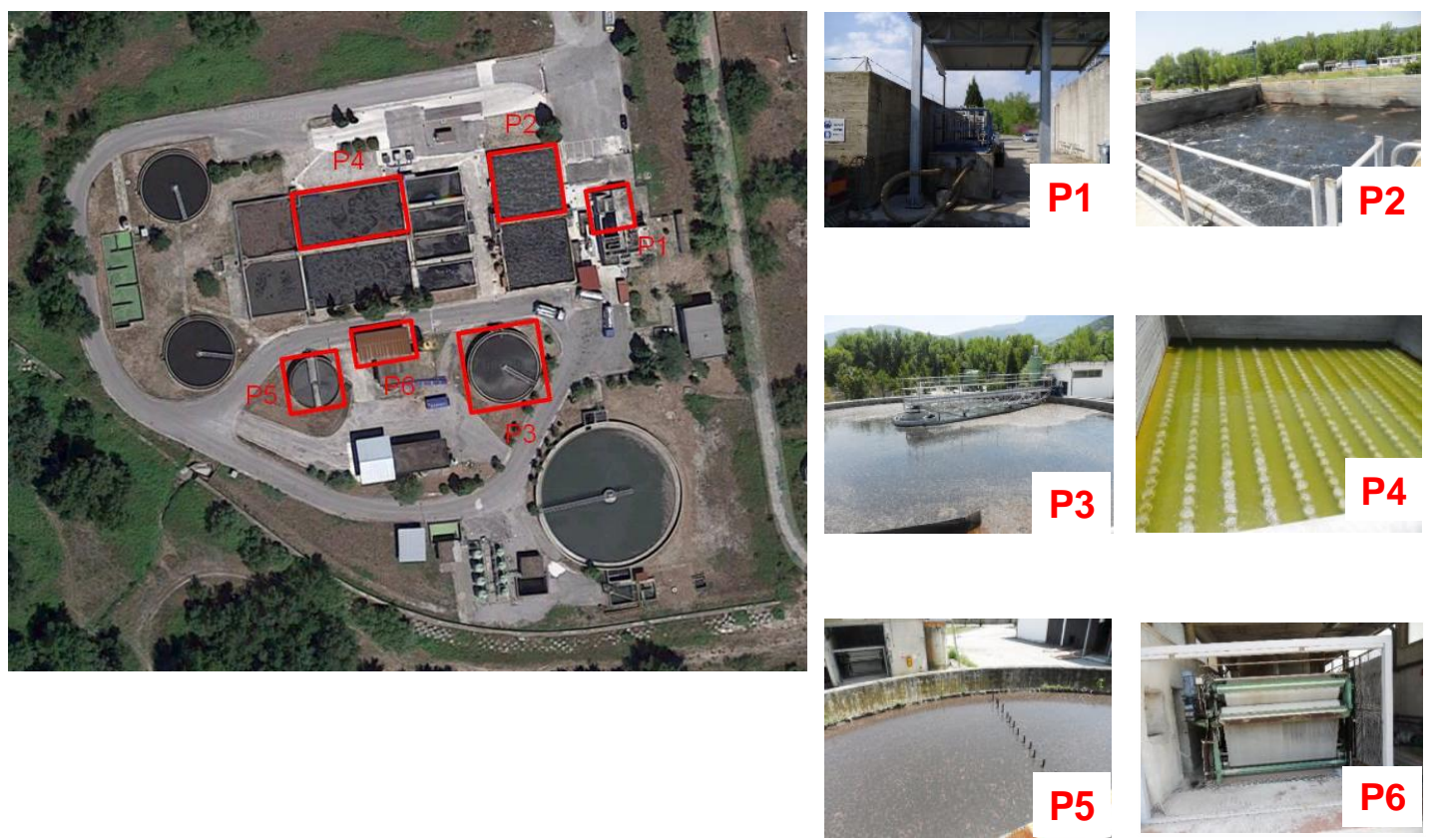

Figure 1. Investigated LWTP and odour emission sources

Each collected odour samples has been analysed with dynamic olfactometry to calculate the odour concentration $\left(O U_{E} / \mathrm{m}^{3}\right)$. All samples were submitted to the e.nose system to create the qualitative and quantitative 'odour measurement model' (OMM).

\subsection{Odour concentration characterization}

Odour concentration was carried out by dynamic olfactometry according to EN 13725:2003 at the Olfactometric Laboratory of the SEED (Sanitary Environmental Engineering Division) research centre of the University of Salerno, using an olfactometer model T08 by ECOMA, based on the "yes/no" method, relying on a panel 
composed of four trained persons. All the measurements were conducted within $14 \mathrm{~h}$ after sampling, according to Zarra et al. (2012) studies to reduce the variability of the mixture and increase the reliability.

\subsection{Electronic nose and data analysis}

The seedOA (Sanitary Environmental Electronic Device for Odour Application) multisensor system, designed and implemented by the SEED research group of the University of Salerno (IT), was used as e.nose technologies. The seedOA consists of a set of 12 metal oxides non-specific gas sensors (MOS, Figaro, USA Inc.), 2 specific gas sensors (TGS825 for $\mathrm{H}_{2} \mathrm{~S}$ and TGS826 for $\mathrm{NH}_{3}$ ) and 2 internal conditions sensors (humidity and temperature), placed on two different levels of an innovative measurement chamber ( $\operatorname{code}^{\circledR}$ ) (Viccione et al., 2012) patented by the SEED research group. The code $^{\circledR}$ chamber is composed of a hollow cylinder having a volume of $300 \mathrm{~cm}^{3}$ and a central cylindrical diffuser for the flow homogenization and regulation. The design and architecture of the seedAO reflect the human nose, with the two levels that represent the two nostrils (in which are located the same types of sensors in a symmetrical manner) and the processing system that interprets the brain.

Figure 2 shows the scheme of the sensors and their location within the code ${ }^{\circledR}$ measurement chamber of the seedOA.

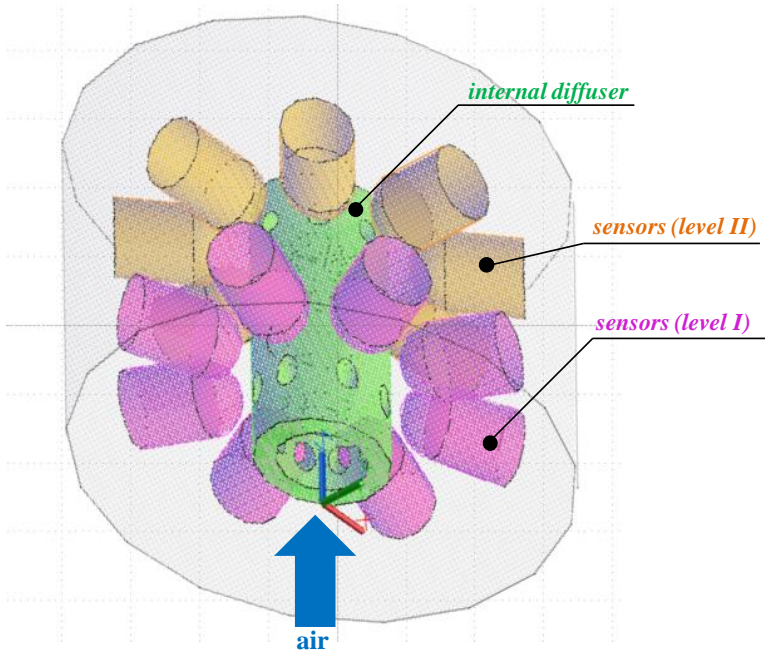

\begin{tabular}{cll}
\hline $\begin{array}{c}\text { code }{ }^{\circledR} \\
\text { LEVEL }\end{array}$ & TARGET GAS & MODEL $\mathbf{N}$. \\
\hline$I, I I$ & Alcohol and organic solvent vapors & TGS822 \\
\hline$I, I I$ & Alcohol and water vapors & TGS880 \\
\hline$I, I I$ & Methane gas & TGS842 \\
\hline$I, I I$ & Volatile Organic Compound & TGS2620 \\
\hline$I, I I$ & Methane & TGS2611 \\
\hline$I, I I$ & Air contaminants & TGS2602 \\
\hline$I I$ & Ammonia (specific) & TGS826 \\
\hline$I I$ & Hydrogen Sulfide (specific) & TGS825 \\
\hline$I$ & LP gas (e.g. propane and butane) & TGS2610 \\
\hline$I$ & Water Vapor Detection & TGS2180 \\
\hline
\end{tabular}

Figure 2. Sensors scheme and location in the code ${ }^{\circledR}$ measurement chamber of the seedOA

All samples were analysed according to the procedure proposed by Giuliani et al. (2012) with a cycle type "odour - non-odour", a running time of 10 minutes per sample and the extraction of the registered data set relating to only the last one minute of the 10-minute analysis.

The measurements provided by the device are electrical resistance (R) $(K \Omega)$, recorded every 2 seconds. The supervised Linear Discriminant Analysis (LDA) processing techniques was applied to create the qualitative OMM, while the Partial Least Squares (PLS) method was used to develop the quantitative OMM, correlating the acquired fingerprint with the olfactometric data, determined by dynamic olfactometry. All statistical analysis were carried out using the software Statistica ${ }^{\circledR}$ (StatSoft srl, It).

\subsection{Optimization procedures and studies}

The performance of the seedOA system ca be increased by optimising their sensor array. To this purpose, nine types of e.nose array configurations (C1-C9) were investigated and compared:

- C1: all the sensors array of the measurement chamber;

- $\quad$ C2: only the sensors array located at the first level;
- C3: only the sensors array located at the second level;

- C4: only the specific gas sensors (referring to $\mathrm{NH}_{3}$ and $\mathrm{H}_{2} \mathrm{~S}$ );

- C5-C9: couple of identical sensors or sensors referred to the same target gas, located of both levels:

- C5: sensors for alcohol and organic solvent vapours (TGS822);

- C6: sensors for methane (TGS842, TGS2611);

- C7: sensors for alcohol and water vapours (TGS880);

- C8: sensors for volatile organic compounds (TGS2620);

- C9: sensors for air contaminants (TGS2602).

For each investigated configurations the corresponding data sets, extracted from the complete acquired database, were processed with the LDA and PLS techniques. 


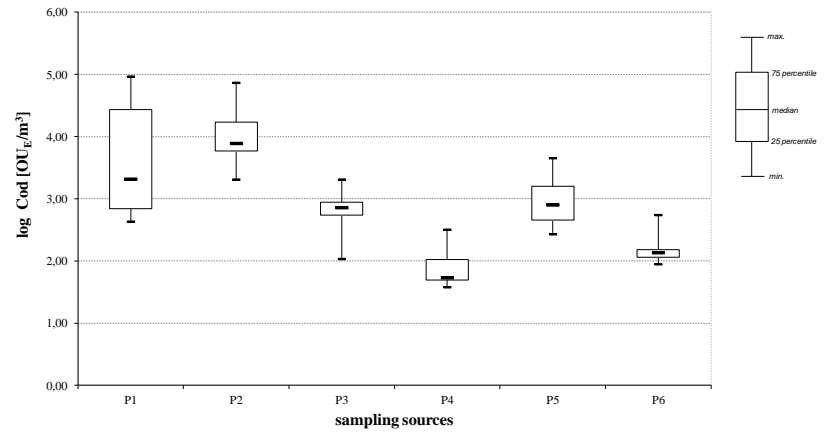

Figure 3. Box-Whisker diagrams on measured odour concentrations at LWTP investigated sources

\section{Results and discussions}

\subsection{Odour concentration characterization}

Figure 3 reports the results of the olfactometric analysis at each investigated source at the LWTP plant, over the whole monitored period in terms of Box-Whisker diagrams. The results show that the highest odour concentration (Cod) among the investigated sources were detected at the liquid waste-wastewater receiving unit $\left(\mathrm{P} 1,92^{\prime} 682 \mathrm{OU}_{\mathrm{E}} / \mathrm{m}^{3}\right)$, while the lowest were measured at the aeration basin (P4, $38 \mathrm{OU}_{\mathrm{E}} / \mathrm{m}^{3}$ ). The largest variability of the determined odour concentrations was recognized at the receiving unit, related to the different type of treated waste (e.g. leachate from landfill, sludge from dairy waste, leachate from refuse derived fuel plants). The preliminary units $(P 1, P 2)$ of the waste/wastewater treatment line present the highest average odour concentrations, while the secondary treatments of the waste/wastewater treatment line shows the lowest average values in terms of Cod. Between the sludge treatments, the thickening shows the highest average Cod values. These results are in line with literature studies that identify influent liquid waste thank as one of the most relevant units in LWTPs in terms of odour concentrations (Belgiorno et al., 2012; Zarra et al., 2016).

\subsection{Optimization studies}

Table 1 highlights the accuracy percentages of correct classification for each investigated class (source), for each analysed seedOA array configuration, applying the LDA technique. The classification of each observation is based on the Mahalanobis distance between the observation and the centroid of each group.

The results show the different accuracy in terms of source classification for different array configurations, thus demonstrating the importance of the proposed procedure to investigate the most suitable sensor array configuration. The total percentage of correct classification of all data is calculated considering a different multiplication weight for the odour samples ( $\left.\mathrm{WP1}_{\mathrm{P} \text {-P6 }}=0,090909\right)$ and for the odourless samples ( $w_{\text {odourless }}=0,454545$ ), defined taking into account the different number of collected samples over the monitoring period ( 9 for each odour sources and 45 for the odourless point).

For the analysed case study, the configuration C1 (all sensors array) provides the most robust classification odour model, with a percentage of $92,93 \%$, while the configuration that gives the lowest reliability are the ones that use only the TGS2602 sensors $(62,63 \%)$.

The odour sources related to the preliminary treatments of the waste/wastewater treatment line and to the sludge treatments showed the highest average values of correct classification in all investigated configurations. These odour sources are the only ones that reach an accuracy percentage of $100 \%$, but not in every analysed configuration: the higher the detected odour concentration on the sources is, the more reliable is the attribution of their observation to its odour class (higher percentage of correct classification).

The results of the quantitative PLS model applied on the acquired data in the different investigated configurations are reported in Table 2 as forecast probability indexes $\left(R^{2}\right)$. Likewise, to the application to the LDA model, the PLS application shows different values of the confidence level between the odour concentrations determined by olfactometric measurement and predicted by the PLS model, analysing different array configurations. The highest correlation coefficient is calculated even in this case considering the entire array of sensors (C1) $\left(R^{2}=0,94\right)$.

Table 1. Qualitative classification rates with LDA model in the investigated sensor array configurations

\begin{tabular}{|c|c|c|c|c|c|c|c|c|c|}
\hline \multirow{3}{*}{$\begin{array}{l}\text { Sampling } \\
\text { source }\end{array}$} & \multicolumn{9}{|c|}{ \% Correct classification } \\
\hline & \multicolumn{9}{|c|}{ Type of array configuration } \\
\hline & C1 & $C 2$ & C3 & C4 & C5 & C6 & $C 7$ & $C 8$ & C9 \\
\hline$P 1$ & 100,00 & 77,78 & 100,00 & 77,78 & 77,78 & 44,44 & 77,78 & 77,78 & 77,78 \\
\hline$P 2$ & 100,00 & 100,00 & 77,78 & 55,56 & 100,00 & 100,00 & 100,00 & 100,00 & 55,56 \\
\hline P3 & 77,78 & 55,56 & 55,56 & 44,44 & 22,22 & 44,44 & 00,00 & 00,00 & 00,00 \\
\hline P4 & 55,56 & 44,44 & 55,56 & 22,22 & 11,11 & 11,11 & 00,00 & 22,22 & 00,00 \\
\hline$P 5$ & 88,89 & 44,44 & 100,00 & 55,56 & 44,44 & 44,44 & 22,22 & 77,78 & 44,44 \\
\hline P6 & 100,00 & 77,78 & 77,78 & 77,78 & 44,44 & 55,56 & 11,11 & 11,11 & 44,44 \\
\hline Odourless & 100,00 & 100,00 & 100,00 & 95,56 & 95,56 & 100,00 & 100,00 & 100,00 & 93,33 \\
\hline All data & 92,93 & 81,82 & 87,88 & 73,74 & 70,71 & 72,73 & 64,65 & 71,72 & 62,63 \\
\hline
\end{tabular}


Table 2. Correlation index of odour concentrations measured by dynamic olfactometry and predicted by PLS model applications in the various investigated seedOA sensors array configurations

\begin{tabular}{|c|c|c|c|c|c|c|c|c|c|}
\hline \multirow{2}{*}{$\begin{array}{l}\text { Correlation } \\
\text { index }\end{array}$} & \multicolumn{9}{|c|}{ Type of array configuration } \\
\hline & C1 & C2 & C3 & C4 & C5 & C6 & $C 7$ & $C 8$ & C9 \\
\hline$R^{2}$ & 0,94 & 0,81 & 0,84 & 0,67 & 0,75 & 0,68 & 0,66 & 0,69 & 0,61 \\
\hline
\end{tabular}

\section{Conclusions}

An optimised procedure for the training of a multisensor array system improves their performance through the optimisation of the sensor array selection. The results of the investigations on different sensors array configurations show the existence of different accuracy in terms of odour source classification and correlation coefficients of odour concentrations measured by dynamic olfactometry and predicted by PLS model applications. The present work demonstrates the importance of the analysis of the most suitable sensor array configuration to optimise the e.nose performance and to maximise their ability to recognise qualitatively and quantitatively odours in ambient air. For the investigated LWWTP the optimum array configuration was identified as the one using the entire sensors array for both qualitative and quantitative OMM.

The research highlights the importance to have e.nose technologies that allows the possibility to change and select their array of sensors for the specific analysed case study, to increase their reliability and repeatability. Moreover, the research confirms the impossibility to define a standard option for the e.nose technologies that represents the optimal measurement conditions in every case.

\section{References}

Belgiorno V., Naddeo V., and Zarra T. (2012), Odour Impact Assessment Handbook, John Wiley \& Sons, Inc., 288 p., ISBN: 978111996928-0.

Gardner J.W. and Bartlett P.N. (1994), A brief history of electronic noses, Sensors \& Actuators, B: Chemical, 18, 210-211.

Giuliani S., Zarra T., Nicolas J., Naddeo V., Belgiorno V. and Romain A.C. (2012), An alternative approach of the e-nose training phase in odour impact assessment, Chemical Engineering Transactions, 30, 139-144.

Guillot J.-M. (2016), E-noses: Actual Limitations and Persepctives for Environmental Odour Analysis, Chemical Engineering Transactions, 54.

Muñoz R., Sivret E.C., Parcsi G., Lebrero R., Wang X., Suffet I.H. and Stuetz R.M. (2010), Monitoring techniques for odour abatement assessment, Water Research, 44(18), 5129-5149.

Röck F., Barsan N. and Weimar U. (2008), Electronic nose: current status and future trends, Chemical Reviews, 108(2), 705-725, doi: $10.1021 /$ cr068121q.

Romain A.C. and Nicolas J. (2010), Long term stability of metal oxide-based gas sensors for e-nose environmental applications: An overview, Sensors \& Actuators, B: Chemical, 146, 502-506.

Viccione G., Zarra T., Giuliani S., Naddeo V. and Belgiorno V. (2012), Performance study of e-nose measurement chamber for environmental odour monitoring, Chemical Engineering Transactions, 30, 109-114.
Zarra T., Naddeo V., Belgiorno V., Reiser M., Kranert M. (2008), Odour monitoring of small wastewater treatment plant located in sensitive environment, Water Science and Technology, 58, 89-94.

Zarra T., Reiser M., Naddeo V., Belgiorno V. and Kranert M. (2012), A comparative and critical evaluation of different sampling materials in the measurement of odour concentration by dynamic olfactometry, Chemical Engineering Transactions, 30, 307-312, ISSN: 1974-979.

Zarra T., Reiser M., Naddeo V., Belgiorno V. and Kranert M. (2014), Odour emissions characterization from wastewater treatment plants by different measurement methods, Chemical Engineering Transactions, 40, 37-42, ISSN: 1974979.

Zarra T., Naddeo V. and Belgiorno V. (2016), Characterization of odours emitted by liquid waste treatment plants (LWTPs), Global NEST Journal, 18(4), 721-727. 